\title{
The formation and stacking faults of Fe and Cr containing Laves phase in Zircaloy-4 alloy
}

Guoqin Cao ${ }^{1,2}$, Yifan Yun ${ }^{1,2}$, Lei Yang ${ }^{1,2}$, Gaihuan Yuan ${ }^{3}$, Qiang Yue ${ }^{3}$, Guosheng Shao ${ }^{1,2+}$, Junhua $\mathrm{Hu}^{1,2^{*}}$

\begin{abstract}
The crystallographic characterization and defect structure of precipitates plays a key role in the properties of $\mathrm{Zr}$ alloys. The precipitates in Zircaloy-4 alloy are studied in this work. The $\mathrm{Zr}-$ $\mathrm{Fe}-\mathrm{Cr}$ particles are identified as the dominant precipitates at room temperature with $\mathrm{C} 14$ or $\mathrm{C} 15$ type Laves structure. The $\mathrm{Fe} / \mathrm{Cr}$ ratio of $\mathrm{C} 15$ type $\mathrm{Zr}-\mathrm{Fe}-\mathrm{Cr}$ phase is slightly lower than that of $\mathrm{C} 14$ type phase. The $\{0001\}$ stacking faults in $\mathrm{C} 14$ phase is observed and analyzed for the first time. Some new orientation relationships of $\mathrm{C} 14$ and $\mathrm{C} 15$ phases with $\alpha-\mathrm{Zr}$ are identified.
\end{abstract}

Key words: Nuclear materials; Precipitates; Crystallographic characterization; Orientation relationship; $\mathrm{Fe} / \mathrm{Cr}$ ratio

\section{Introduction}

$\mathrm{Zr}$ alloys are currently heavily used in nuclear reactor as cladding materials. The primary advantages associated with $\mathrm{Zr}$ for fuel cladding are very low absorption of neutrons, good fabricability and strength. The cladding materials within a reactor core must tolerate the exposure to coolant (high temperature water, liquid metals, gas, or liquid salts), intense field of high energy neutrons and gradients in temperature. Degradation of materials in this environment can lead to reduced performance or even sudden failure ${ }^{[1,2]}$.

Thus efforts should been taken to increase the properties of Zr-based alloys at high burn-up environment. This can be achieved through the introduction of alloying elements with low absorption cross-section of thermal neutrons to induce solution and/or precipitate strengthening while maintaining good corrosion resistance ${ }^{[3]}$. Only a limited number of alloying elements are suitable for cladding $\mathrm{Zr}$ alloys, with their acceptable contents being fairly low. Due to the limited 
solubility of alloying elements in $\alpha-\mathrm{Zr}$, most of them tend to precipitate as second phase particles (SPPs), which strongly influence the properties of $\mathrm{Zr}$ alloys ${ }^{[4,5]}$.

The optimized corrosion performance of $\mathrm{Zr}$ alloys was achieved when the fine SPPs were uniformly precipitated in $\alpha-\mathrm{Zr}$ matrix ${ }^{[6,7]}$. Meanwhile, the weak anti-radiation ability of precipitates with planar defect makes them prone to amorphization and elemental migration under neutron irradiation, which would change chemical compositions of the matrix as well as the type of precipitates, thereby lowing the corrosion resistance of $\mathrm{Zr}$ alloys ${ }^{[8,9]}$. Thus, it is significant to further analyze the properties and characteristics of second phases, which can provide a material basis for improving the performance of $\mathrm{Zr}$ alloys during reactor operation. This work is focused on the precipitates in a thermomechanically processed Zircaloy-4 alloy, with particular interest in orientation relationship, composition distribution and defects structure.

\section{Experimental Methods}

The ingots of alloy with the typical Zircaloy-4 composition ( $\mathrm{Zr}-1.2 \mathrm{wt} . \% \mathrm{Sn}-0.2 \mathrm{wt} . \% \mathrm{Fe}-0.1 \mathrm{wt} . \%$ $\mathrm{Cr}^{[10]}$ ) were prepared by vacuum arc melting, using self-consuming electrode. Each ingot was forged at $1070{ }^{\circ} \mathrm{C}$ into feeding blocks, then water-quenched down to room temperature and annealed in vacuum at $630^{\circ} \mathrm{C}$ for $1.5 \mathrm{~h}$ before being hot-rolled at $700{ }^{\circ} \mathrm{C}$ into sheets of $2 \mathrm{~mm}$ in thickness. The hot-rolled sheets were finally annealed at $650{ }^{\circ} \mathrm{C}$ for $1.5 \mathrm{~h}$ to achieve complete re-crystallization. Thin foils for transmission electron microscopy (TEM) analysis were mechanically polished to about $60 \mu \mathrm{m}$ in thickness, and then the central region of each disc was dimple-polished down to about 20 $\mu \mathrm{m}$ in thickness. Finally, the foils were polished by ion milling at $4 \mathrm{KeV}$. To make reliable results, dozens of $\mathrm{Zr}$-Fe-Cr particles from more than 10 grains in Zircaloy-4 alloy have been analyzed using TEM (JEM 2010FEF microscope) equipped with an energy dispersive X-ray detector.

\section{Results and discussion}

The precipitates of Zircaloy-4 alloy are mainly $\mathrm{Zr}-\mathrm{Fe}-\mathrm{Cr}$ phase, the structure of which is similar to $\mathrm{ZrCr}_{2}$ Laves phase, and the stoichiometric formula is $\mathrm{Zr}\left(\mathrm{Fe}_{\mathrm{x}}, \mathrm{Cr}_{1-\mathrm{x}}\right)_{2}$ with crystalline structure of either C14 (HCP) or C15 type (FCC) ${ }^{[11,12]}$. Both $\mathrm{C} 14$ and $\mathrm{C} 15$ type Laves phases were found in this research. Fig. 1 shows the bright field (BF) image of two typical particles in Zircaloy-4 alloy. The energy dispersive X-ray spectroscopy (EDS) results confirmed that they were $\mathrm{Zr}$-Fe-Cr particles, though the morphology were quite different. The selected area electron diffraction (SAED) patterns 
of each particles have presented accordingly. In Fig. 1(a) the diffraction pattern can be indexed as C14 type phase. The C14 and C36 type phase both belong to Laves phase as hexagonal structure. Only C14 type phase matches the SAED patterns in this work. The orientation relationship(OR) with matrix in Fig. 1A was characterized as $(11 \overline{2} 0)_{\mathrm{spp}} / /(0002)_{\alpha-\mathrm{Zr}}$, $[2 \overline{2} 01]_{\mathrm{spp}} / /[01 \overline{10}]_{\alpha-\mathrm{Zr}}$. On this basis, the atomic configuration of the mentioned OR was reconstructed and shown in Fig. 1(c). The lattice misfit is as small as 0.029 along the [2201] vector. The particle in Fig. 1(b) was indexed as C15 type phase. The typical OR that derived from the SAED pattern B is $(11 \overline{2} 0)_{\mathrm{spp}} / /(0002)_{\alpha-\mathrm{Zr}},[2 \overline{2} 01]$ spp $/ /[0110]_{\alpha-Z r}$. The atomic configuration was illustrated with the lattice mismatch as small as 0.065 along [101] direction.
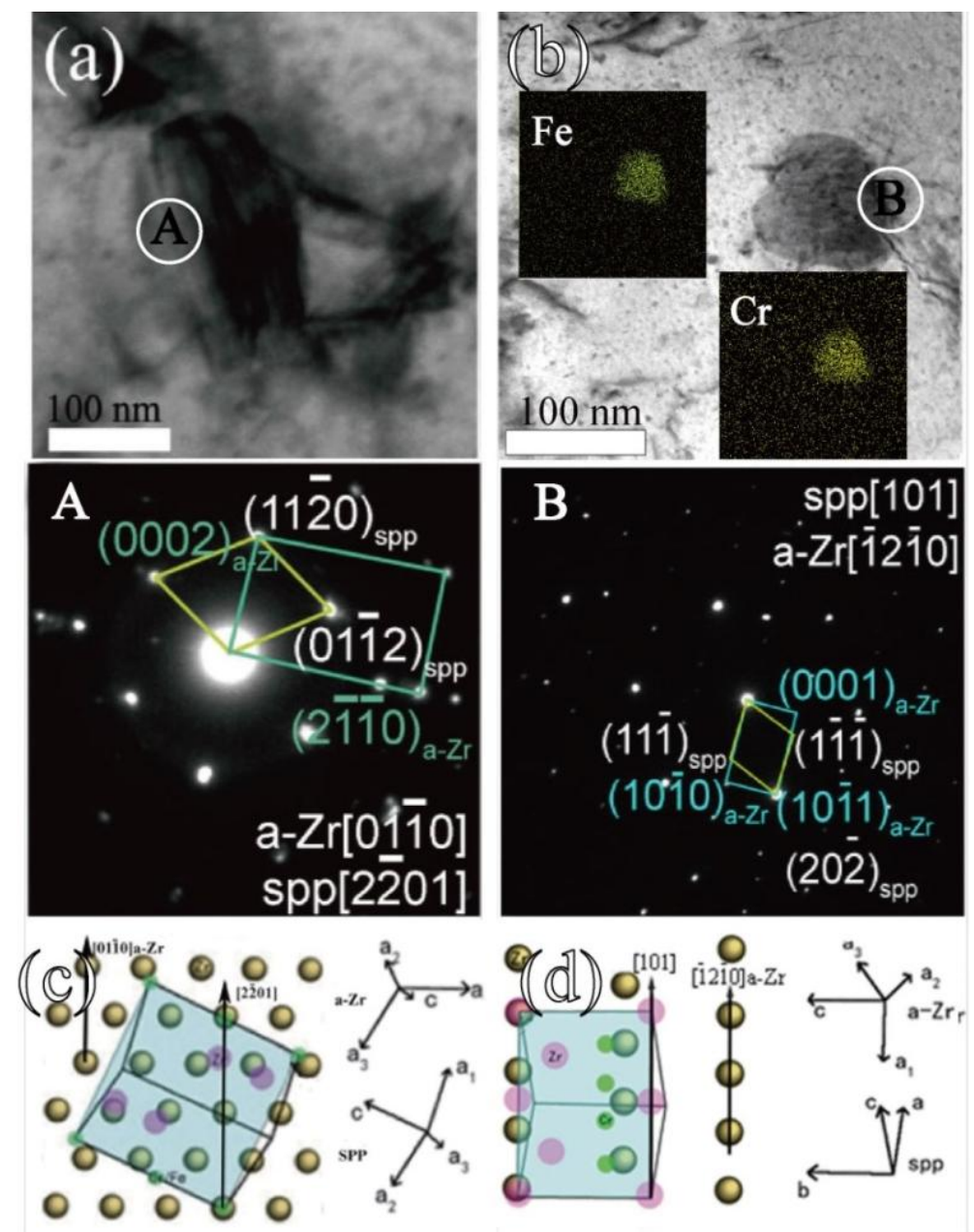

Fig. 1 (a) The bright field image of C14 Laves type phase (b) The bright field image of C15 Laves type phase; A and $\mathrm{B}$ show the corresponding SAED patterns, respectively. The insets in (b) show the mappings of $\mathrm{Cr}$ and $\mathrm{Fe}$. (c) the schematic diagrams of orientation relationship between $\mathrm{C} 14$ phase and $\alpha-\mathrm{Zr}$ (d) the schematic diagrams of orientation relationship between $\mathrm{C} 15$ phase and $\alpha-\mathrm{Zr}$ 
According to the literature report, at room temperature, the $\mathrm{Zr}(\mathrm{Fe}, \mathrm{Cr})_{2}$ particle is hexagonal structure (C14), while this particle is identified as FCC structure (C15) at high temperature ${ }^{[11,12]}$. Elliot reported that the decisive factor for the formation of $\mathrm{C} 14$ phase was the content of $\mathrm{Cr}$, since $\mathrm{Cr}$ can stabilize $\mathrm{C} 14$ hexagonal structure because of its much higher valence electrons/atomic ratio ${ }^{[13]}$.

In this work, dozens of $\mathrm{Zr}-\mathrm{Fe}-\mathrm{Cr}$ particles with size from $100 \mathrm{~nm}$ to $500 \mathrm{~nm}$ were analyzed. SAED patterns proved the formation of two kinds of structure, namely FCC structure and hexagonal structure. The composition and structure of $\mathrm{Zr}-\mathrm{Fe}-\mathrm{Cr}$ phases was summarized and shown in Fig. 2. Because SPPs are very small and embedded into matrix, the characteristic X-rays generated by $\mathrm{Zr}$ that belong to matrix may also be detected. Taking into consideration the influence of matrix we only count $\mathrm{Fe} / \mathrm{Cr}$ atomic ratio. Although the morphology and size varied very much, $\mathrm{Fe} / \mathrm{Cr}$ ratio varied from 2 3. It is interesting to note that $\mathrm{C} 15$ type phase contains more $\mathrm{Cr}$ than $\mathrm{C} 14$ type phase. This may be related to the kinetic factor that the diffusion coefficient of $\mathrm{Fe}$ in $\alpha-\mathrm{Zr}$ matrix is faster than $\mathrm{Cr}^{[14]}$. Thus the formation of $\mathrm{C} 15$ and $\mathrm{C} 14$ type phase is not determined by atoms distribution solely. According to $\mathrm{Zr}$-Cr phase diagram, the $\mathrm{ZrCr}_{2}$ phase is stable with $\mathrm{C} 15$ type structure at low temperature. Yuan also reported that $\mathrm{C} 14$ type $\mathrm{Zr}(\mathrm{Fe}, \mathrm{Cr})_{2}$ retained at room temperature because the transformation to $\mathrm{C} 15$ structure is very sluggish ${ }^{[15]}$.

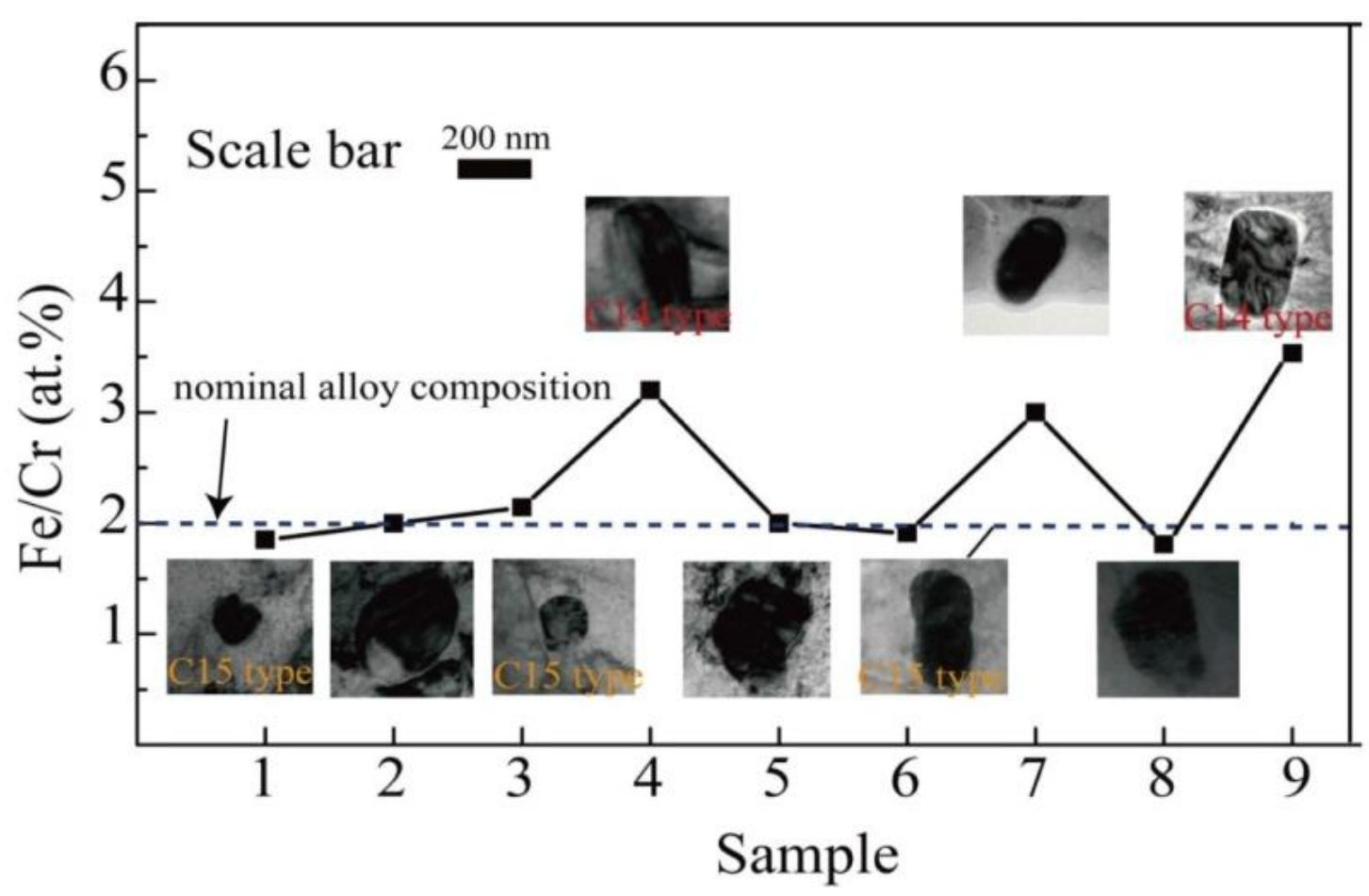

Fig. 2 The $\mathrm{Fe} / \mathrm{Cr}$ atomic ratio of $\mathrm{Zr}-\mathrm{Fe}-\mathrm{Cr}$ SPPs 
Fig. 3 is a set of bright field image and the corresponding SAED pattern of a cuboidal-like phase. The SAED pattern of the precipitate can be indexed as C14-[1210] zone axis. The corresponding OR with $\alpha-\mathrm{Zr}$ is nearly $[\overline{1} 2 \overline{10}]_{\mathrm{spp}} / /[17 \overline{8} 3]_{\alpha-Z r}$ and $(0001)_{\mathrm{spp}} / /(1 \overline{102})_{\alpha-Z r}$. There are optimum lattice matching on this relationship, which may lower the strain energy of nucleation and promote the formation of cuboidal-like precipitation in $\mathrm{Zr}$ matrix ${ }^{[16]}$.

The diffraction pattern of the precipitate shows streaking along the [0001] vector, owing to the presence of stacking faults in the (0001) plane. The high magnification image in Fig. 3(c) exhibited contrast stripe, which provided evidence for the presence of long period stacking variants in the C14 structure. From SAED (Fig. 3b) we can see the $2 \mathrm{H}$ long-period structures existed as Meng reported ${ }^{[17]}$. Long period structure in Laves phase is mainly affected by the ordering of component and stacking faults ${ }^{[18]}$. The orderly occupation of solutes on $\mathrm{C} 14$ lattice probably originated from the sufficient migration since the stacking faults in precipitates provide sufficient space for the solute atoms to migrate.

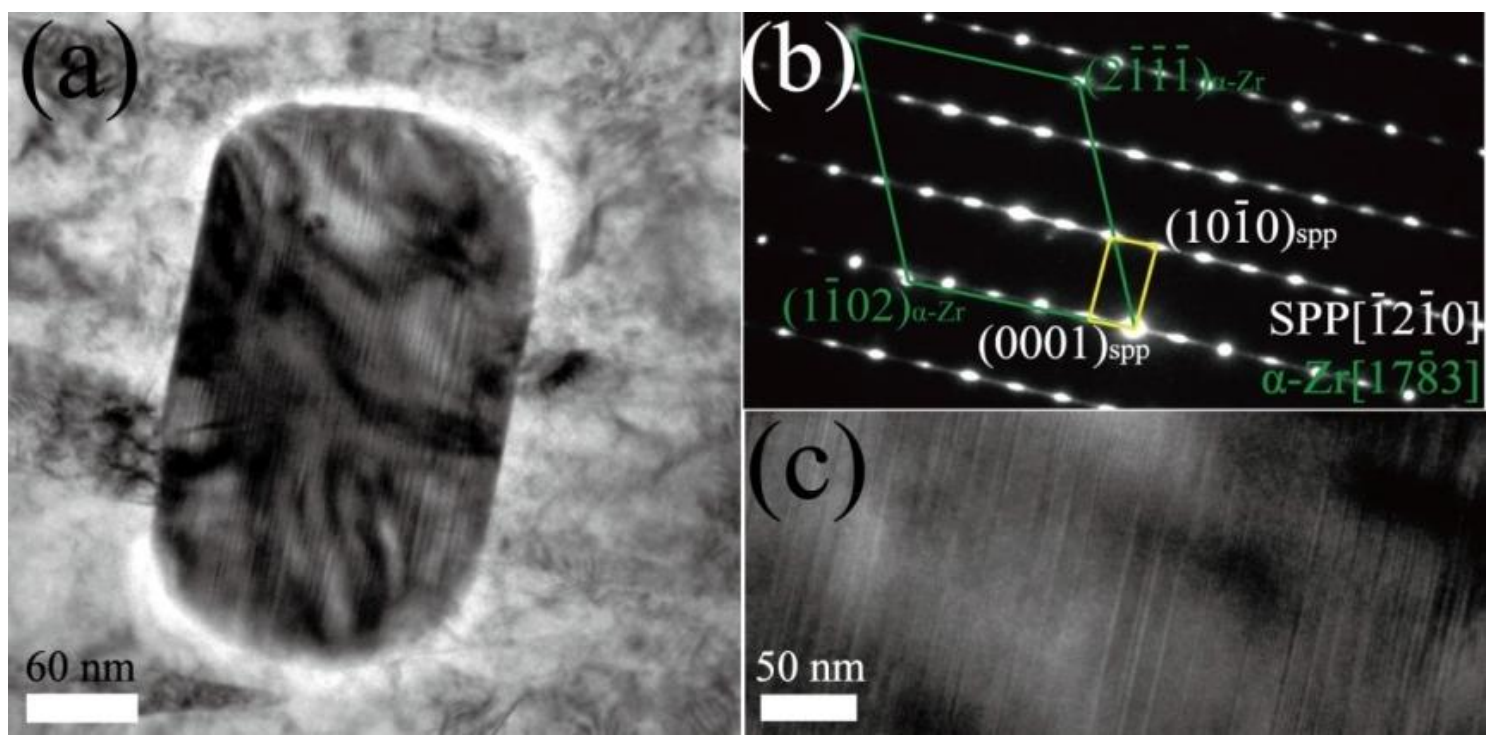

Fig. 3 (a) Bright field image of $\mathrm{C} 14-\mathrm{Zr}(\mathrm{Fe}, \mathrm{Cr})_{2}$ phase; (b) The corresponding SEAD pattern; (c) high magnification image of $\mathrm{C} 14-\mathrm{Zr}(\mathrm{Fe}, \mathrm{Cr})_{2}$ phase. 


\section{Conclusion}

$\mathrm{Zr}(\mathrm{Cr}, \mathrm{Fe})_{2}$ Laves phases as the dominant precipitates in Zircaloy-4 alloy were found with $\mathrm{C} 14$ or C15 type structure. The $\mathrm{Fe} / \mathrm{Cr}$ ratio in $\mathrm{C} 14$ type $\mathrm{Zr}-\mathrm{Fe}-\mathrm{Cr}$ phase is larger than that in $\mathrm{C} 15$ type, which proved that the formation of $\mathrm{Zr}-\mathrm{Fe}-\mathrm{Cr}$ phase was not determined by atoms redistribution solely. As for the C14 structure, the orientation relationship was $(11 \overline{2} 0)_{\mathrm{spp}} / /(0002)_{\alpha-\mathrm{Zr}},[2 \overline{2} 01]_{\mathrm{spp}} / /[01 \overline{10}]_{\alpha-\mathrm{Zr}}$. The orientation relationship of C15 structure was $(20 \overline{2})_{\mathrm{spp}} / /(10 \overline{11})_{\alpha-\mathrm{Zr}},[101]_{\mathrm{spp}} / /[\overline{1} 2 \overline{1} 0]_{\alpha-\mathrm{Zr}}$. The stacking faults in $\{0001\}$ plane were also observed in the ternary C14 Laves phase with a cuboidal-like morphology. Further work need to be done to study the changes of ORs and defects under in suit ion irradiation.

\section{Acknowledgement}

This work was supported by National Science Foundation of China (Grant numbers: 51001091, 111174256, 51571182, 52110774). 


\section{References}

[1] S. J. Zinkle, G. S. Was, Materials challenges in nuclear energy. Acta Mater. 61 (2013) 735 -758.

[2] G. Yuan, G. Cao, Q. Yue, L. Yang, Y. Yun, G. Shao, J. Hu, Formation and fine-structures of nanoprecipitates in ZIRLO, J. Alloy. Compd. 687 (2016) 451-457.

[3] S. Kass, The Development of the Zircaloys. Corrosion of Zirconium Alloys, ASTM STP368, ASTM International, West Conshohocken, PA, 1964, 3-14.

[4] X. Meng, D. O. Northwood, Intermetallic precipitates in zirconium-niobium alloys, ASTM STP 1023 (1989) 478-486.

[5] G. H. Yuan, G. Q. Cao,. Q. Yue, L. Yang, J. H. Hu, G. S. Shao, Formation of nanocrystalline $\delta$-ZrHx in Zircoloy-4: Orientation relationship and twinning, J. Alloy. Compd. 658 (2016) 494-499.

[6] C. M. Eucken, P. T. Finden, S. Trapp-Pritsching, H. G. Weidinger. Influence of chemical composition on uniform corrosion of zirconium-base alloys in autoclave tests, ASTM STP 1023 (1989) 113-127.

[7] J. Huang, M.Y.Yao, C.Y. Gao, X. Liang, J.C. Peng, J.L. Zhang, B.X. Zhou, The influence of second phase particles on the crack formation in oxides films formed on zirconium alloys, Corros. Sci. 99 (2015) $172-177$.

[8] J. A. Faldowski, A. T. Motta, L. M. Howe, et al. Influence of stacking faults and alloy composition on irradiation induced amorphization of $\mathrm{ZrCr}_{2}, \mathrm{ZrFe}_{2}$ and $\mathrm{Zr}_{3}\left(\mathrm{Fe}_{1-\mathrm{x}}, \mathrm{Ni}_{\mathrm{x}}\right), \mathrm{MRS}$ Proceedings. Cambridge University Press, 398 (1995) 183-191

[9] S. Kanazawa, Y. Kaneno, H. Inoue, et al. Microstructures and defect structures in $\mathrm{ZrCr}_{2}$ Laves phase based intermetallic compounds. Intermetallics, 10(8) (2002) 783-792.

[10] J. A. L. Robertson. Zirconium - an international nuclear material. Journal of Nuclear Materials, 100(1) (1981) 108-118.

[11] X. Y. Meng, D. O. Northwood, A TEM study of the $\mathrm{C} 15$ type $\mathrm{Zr}(\mathrm{CrFe})_{2}$ laves phase in Zircaloy-4, J. Nucl. Mater. 136 (1985) 83-90.

[12] W. J. Zhao, B. X. Zhou, Investigation of the intermetallic precipitates in Zircaloy-4. Nuclear Power Engineering., Chengdu, 1991.

[13] R. P. Elliot, W. Rostocker. The occurrence of Laves-type phases among transition elements, Trans. Am. Soc. Met. 50 (1958) 617-633.

[14] W. J. S. Yang, R. P. Tucker, B. Cheng, R. B. Adamson, Precipitates in Zircaloy: identification and the effects of irradiation and thermal treatment, J. Nucl. Mater. 138 (1986) 185-195. 
[15] Y. Shen, O. G. Paasche, On the transformation of ZrCr, Trans. Met. Soc. AIME, 242 (1968) 22412243.

[16] G. Shao, P. Tsakirouolos, A. P. Miodownik, Phase transformations in Ti-40Al-10V, Intermetallics 3 (1995) 315 .

[17] X. Y. Meng, D. O. Northwood, Intermetallic precipitates in Zircaloy-4, J. Nucl. Mater. 132 (1985) 80-87.

[18] M. Yamasaki, M. Sasaki, M. Nishijima, et al. Formation of $14 \mathrm{H}$ long period stacking ordered structure and profuse stacking faults in $\mathrm{Mg}-\mathrm{Zn}-\mathrm{Gd}$ alloys during isothermal aging at high temperature. Acta Materialia, 2007, 55(20): 6798-6805. 